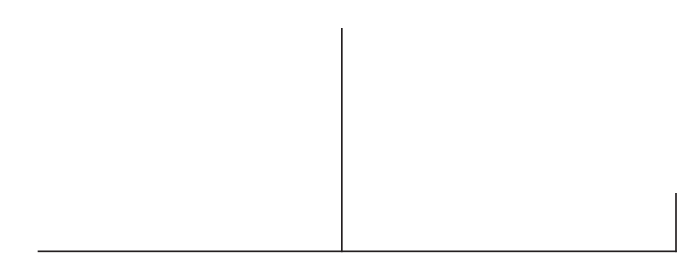

\title{
O processo de subjetivação na clínica psicanalítica com diagnóstico precoce do câncer
}

\author{
Cristina Lindenmeyer Saint-Martin
}

\begin{abstract}
Este artigo dedica-se a trabalhar a problemática do efeito do diagnóstico de câncer em pessoas submetidas às técnicas de detecção precoce dessa doença. Ressalta uma especificidade no trabalho clínico psicanalítico, onde a autora introduz uma reflexão a partir do discurso de Freud após os anos 20. Através de algumas noções, tais como o traumatismo, o masoquismo, a repetição, também coloca no centro de sua experiência clínica os conceitos de trauma e clivagem propostos nos últimos textos de Ferenczi.

Estes conceitos apóiam a reflexão do autor sobre a complexidade transferencial e contratransferencial do trabalho psicanalítico desenvolvido com o paciente canceroso.
\end{abstract}




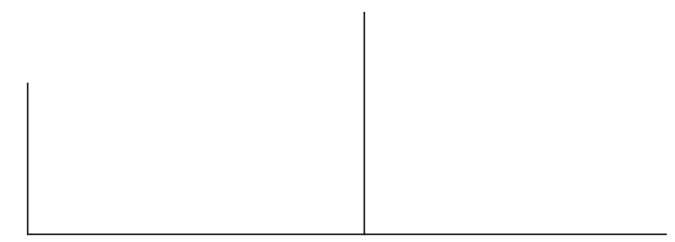

Há alguns anos interesso-me pela questão do corpo na clínica psicanalítica, pelo paradoxo e confusões teóricas que apresenta o trabalho psicanalítico com pessoas apresentando doenças orgânicas. Aliás, foi este interesse que me levou a realizar uma tese de Doutorado em Psicanálise e Psicopatologia Fundamental ${ }^{1}$.

Apresentarei, a seguir, a origem e a problemática desta tese com o objetivo de deixar claro as linhas gerais desenvolvidas e que são, no meu entender, as perspectivas que se abrem a partir da minha forma de articular esta questão do corpo na clínica psicanalítica.

Meu interesse pela questão já existia no Brasil e ampliou quando fui para Paris e onde tive a oportunidade de participar das consultas desenvolvidas por P. Marty na L'IPSO (Institut Psychosomatiques de Paris) e através de minha prática em psicoterapia analítica exercida em um hospital francês especializado em doenças sanguíneas, imunitárias e tumorais, seguida de supervisão com Joyce McDougall.

Esse trabalho, nesse contexto extremamente especializado, sobretudo no tratamento do câncer em todas as suas formas, consistia em receber pessoas, hospitalizadas ou em ambulatório, para psicoterapia ou apenas consultas eventuais.

Antes de continuar gostaria de salientar três aspectos da demanda do sujeito a respeito do trabalho psicoterapêutico e do analista e que deram uma especificidade metodológica ao meu trabalho:

1. Os pacientes estavam hospitalizados ou em ligação com o hospital para um tratamento médico.

2. Esses pacientes, na sua maioria, tinham sido submetidos a rituais de detecção precoce da doença.

3. A decisão de entrar e/ou seguir um processo analítico se dava após o parecer do médico, após o diagnóstico da doença.

Quer dizer algo muito importante, ou seja, o sujeito não tinha acesso ao processo analítico que eu poderia estabelecer com ele, nem

1. Tese defendida em janeiro de 1998, na Universidade Paris VII, com direção do Professor Pierre Fédida. 
eu a ele; eu só poderia existir no espaço subjetivo que iríamos construir, através do médico e do hospital.

Tal situação caracterizava e circunscrevia a demanda de uma forma muito particular. Então, após identificar esses aspectos fui levada a requestionar o modelo psicanalítico tradicional e o modelo psicossomático. ${ }^{2}$

Este questionamento se construía assim:

- Como compreender essa complexidade do trabalho psicoterapêutico: a transferência lateral com a equipe médica, a realidade de um corpo doente, as particularidades transferenciais e contratransferenciais?

- Os discursos que atravessam atualmente o campo psicanalítico sobre a questão do corpo respondem a esta clínica? Ou estariam em relação a um outro tipo de experiência subjetiva?

- O modelo psicossomático, que não é mais o modelo psicanalítico clássico, poderia responder a esta clínica?

- Se o modelo metapsicológico se acha indissociável da situação clínica e requer uma tradução a partir dessa situação, a questão que se coloca é saber qual seria o lugar que ocupa a teorização psicanalítica, qual sua especificidade nesse contexto.

O que sublinho é a existência, em termos da história das idéias, de uma distância entre a elaboração teórica e a situação clínica, distância que aparece como uma perda do sentido próprio da metapsicologia. Requestionar o modelo metapsicológico neste contexto exigia uma transformação de paradigma, o que quer dizer a renovação da questão da transferência que, nesse contexto, assume uma relevância muito especial e que considero um caminho privilegiado nesta clínica.

Enfim, para propor este trabalho de pesquisa surge a idéia de propor como eixo da questão no campo clínico e no contexto teórico um requestionamento da visão clássica e da psicossomática. É necessário, então, identificar limites não somente da compreensão do que ocorria nessa situação clínica, mas principalmente reconhecer uma insatisfação com a forma de intervir e com as interpretações teóricas sobre esse assunto.

Partindo desse contexto clínico atual pude identificar um aspecto que chamou minha atenção. O discurso repetitivo que utilizavam meus pacientes deixavam aparecer a insistência de um aspecto que designei pela expressão: constituição do estado de doença. O que recobre essa expressão é a instauração de uma percepção corporal à partir do momento que o médico anuncia: Você está com câncer.

2. O modelo da escola psicossomática francesa. 


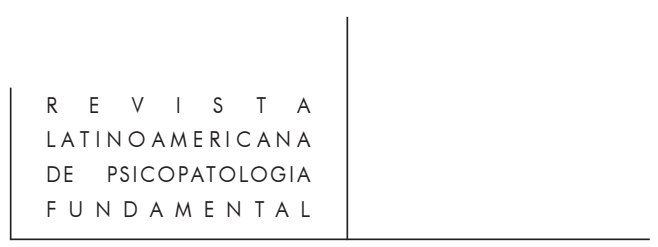

O discurso médico carregado de autoridade provoca uma eclosão na vida psíquica do sujeito, e os efeitos dessa eclosão constituem uma problemática.

Toda atividade psíquica do sujeito converge para este efeito e paradoxalmente toda atividade terapêutica, e posteriormente psicoterapêutica, ficam submergidos neste contexto.

E verdade que uma das características do câncer, segundo o discurso da medicina moderna, é poder se desenvolver em silêncio, sem que o sujeito, ao menos nas primeiras fases da doença, o sinta de forma dolorosa.

As técnicas atuais, particularmente desenvolvidas em hospitais especializados, permitem aos médicos detectar o desenvolvimento dessa doença graças às diversas investigações no corpo do sujeito e antes mesmo que este tenha percebido qualquer modificação em seu próprio corpo. Estas técnicas são tão sofisticadas que dão aos médicos a possibilidade de aceder aos lugares reconhecidos como os mais profundos do corpo humano, a sua organização celular.

Este corpo é então reconhecido como doente e identificado na sua dimensão objetiva, onde a observação, o olhar e o diagnóstico vão ter o poder de identificar e de rastrear as possíveis representações do corpo, a partir deste momento reconhecido doente. Os vários exames, as radiografias etc. vão garantir este discurso.

É então o saber médico que inaugura a presença da doença e identifica o paciente com seus aspectos mórbidos, sem que este tenha percebido qualquer sensação corporal que possa indicar que algo se passa com ele. Quer dizer, é a intervenção do saber médico que desenvolve no sujeito o reconhecimento de que ele tem uma doença grave e que se encontra ameaçado de morte.

Poderíamos pensar que o sujeito se encontra neste momento em uma espécie de negação e que durante todo este tempo da negação a doença evolui. Mas as coisas, segundo a nossa forma de pensar, são mais complexas e nos levam a fazer uma certa revisão do conceito de negação neste contexto atual.

Nesta situação completamente nova da medicina, onde a doença é pensada como função, existe uma transformação do modelo de subjetivação da doença. Isto posto, poderíamos nos deter nesta idéia, que legitima todo nosso trabalho, segundo a qual a situação de doença que é vivida pelos nossos pacientes nasce de dois pontos:

1. A renúncia ao direito a uma vida psíquica, uma espécie de clivagem entre seu corpo e seu psiquismo.

2. A instauração de uma situação de terror, uma situação puramente traumática.

Como então se constrói uma demanda de psicoterapia em um sujeito que não dispõe da experiência da dor para fazer intervir seu psiquismo? Como esta 
clínica, construída a partir de uma modificação essencial da idéia de doença, a partir de uma modificação do modelo de subjetivação da doença, se constrói?

Nesta perspectiva fizemos uma distinção entre dois aspectos, geralmente tratados como fazendo parte de uma só e mesma problemática: de um lado, o discurso médico vivido como terror e, do outro, a constituição da experiência da doença à partir dos fantasmas pessoais de cada sujeito.

Por esta razão foi necessário revisar uma questão que ultrapassa o objetivo de nosso trabalho: sublinhar a evolução própria da medicina até os dias atuais. Como se operou uma medicina baseada em conhecimentos genéticos e que antecipa sobre um estado de doença sem que o sujeito se sinta doente. $\mathrm{O}$ sujeito passa a ser reconhecido paciente antes mesmo de se sentir doente.

Nesta dimensão histórica o que se pode notar, apoiado nos trabalhos de Canguilhem ${ }^{3}$, Foucault ${ }^{4}$ e Clavreul $^{5}$, é que a medicina, quando começa a se pretender preventiva, o mecanismo de tratamento da doença vai ser separar e isolar o corpo em função de seus limites anatômicos. Este contexto anatomopatológico, característica do século XIX, dirá onde se acha localizada a lesão. Quer dizer, existe um ponto de partida e a solução é achar este ponto, onde a doença está fixada.

Mas aos poucos a medicina se dá conta de que existe um lado subjetivo que pode influenciar a eficácia da terapêutica. A psicanálise, nesse momento, representou um interlocutor para esta dificuldade ${ }^{6}$. Por exemplo, os trabalhos de Balint e o movimento psicossomático vão ser apreendidos neste contexto. O que vem colaborar com a necessidade da contratação de psicólogos ou psicanalistas nos serviços hospitalares.

O apoio no discurso psicanalítico sobre a subjetividade vai garantir a possibilidade da utilização e eficácia da terapêutica. Esta situação ainda sofre modificações. $\mathrm{O}$ discurso médico não procura mais diagnosticar a partir de sinais que constituem uma entidade clínica. Atualmente a situação se inverte: o diagnóstico vai ser dado a partir dos protocolos já existentes. Pré-existe uma resposta terapêutica. Transformação brutal da situação, pois aquele que antes formulava a demanda, atualmente se acha transformado em paciente antes de se sentir doente.

O fato de sentir algo, um sofrimento, uma dor, que o leve a consultar, permite ao sujeito formular uma demanda bastante diferente desta onde o

3. G. Canguilhem. Le normal e le pathologique. Paris, PUF, 1994.

4. M. Foucault. Naissance de la clinique. Paris, PUF, 1993.

5. J. Clavreul. L’ordre médical. Paris, Seuil, 1978.

6. J. Birman. Enfermidade e loucura. Sobre a medicina das inter-relações. Rio de Janeiro, Campos, 1980. 


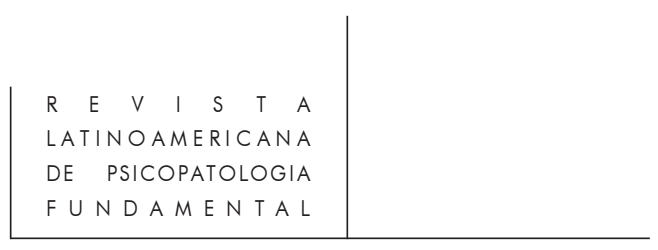

diagnóstico se antecipa. Estamos face a uma outra realidade clínica e provavelmente a uma outra realidade metapsicológica.

Essa situação completamente nova acarreta uma atmosfera depressiva, uma situação de terror face a algo que o paciente não sente, mas tem de encarar.

Esse efeito que chamei de violência terapêutica no momento do anunciado diagnóstico é vivido como uma perda das figuras protetoras internas. Essas figuras protetoras internas não protegem mais quando um outro investido como portador do saber anuncia: você está com câncer. Essas figuras protetoras internas, que são a base das identificações e dos investimentos corporais, quando perdidas impulsam o sujeito ao elemento persecutor e traumático. O sujeito se instala em uma posição de identificação ao agressor, segundo os termos de Ferenczi ${ }^{7}$, como a uma bóia de salvamento. Tudo se passa como se o outro, transferido na figura do médico, viesse a ser quem tem o poder sobre ele. Isso porque ao mesmo tempo que o médico anuncia a morte, ele também propõe a cura. Isso seria o núcleo de uma posição sadomasoquista.

Estaríamos, aí, face à presença de um outro modelo. O modelo anterior de subjetividade da doença é de identificação da doença à angústia, que facilitaria a experiência transferencial. O modelo atual é o modelo depressivo onde o trabalho do analista consiste em transformar essa aparente depressividade em angústia, o que quer dizer duas formas diferentes de entrada na transferência.

Quando o discurso médico é pego como fazendo força de lei, pego como uma forma de gozo, pode esse sujeito aceitar a se confrontar com essa dimensão do vazio necessária como potencial de elaboração?

Por exemplo, pessoas que declaram que durante muito tempo pareciam procurar em seus corpos uma doença e que, quando encontram, parecem aliviadas. Como uma utilização necessária do sintoma orgânico. Como lembra Pierre Fédida em seu texto "L'hypocondrie du rêve", estas pessoas estão a procura de uma doença como uma forma de negociar com uma angústia primitiva o que permitiria a essa mesma angústia um lugar de expressão. Como se o que estivesse em jogo fosse uma atitude defensiva e prazerosa contra o irrepresentável da morte, o que precipitaria o sujeito a uma última compulsão a repetição, ou uma atitude de nenhuma resistência à morte (morte real, morte no real).

Se existe a possibilidade de cair doente sem sinal algum, baseado no termo "silêncio dos órgãos" utilizado por Leriche, este funcionamento hipocondríaco

7. S. Ferenczi. Oeuvres complètes, vol. IV. Paris, Payot, 1982. Journal clinique. Paris, Payot, 1985.

8. P. Fédida. "L'hypocondrie du rêve", in Le corps du vide e l'espace de séance, Paris, Jean Pierre Delarge (Ed.), 1977.

9. Ver G. Canguilhem. Op. cit. 
fica facilmente capturado pela maquinaria médica e a teorização psicanalítica neste contexto não somente pode reforçar essa conduta hipocondríaca, como servir de meio de normatização.

Somos então levados a repensar o estatuto psicopatológico de nossos pacientes. Em que, a partir das questões sublinhadas neste contexto clínico, nosso discurso difere das interpretações que atravessam o campo psicanalítico?

É verdade que estes discursos interrogam as formas particulares de organização pulsional, mas situar nossos pacientes nestes modelos seria para nós um erro. O que nossos pacientes apresentam não é necessariamente uma experiência de somatização, nem de conversão.

Do ponto de vista de nossos pacientes, a doença não aparece como efeito de um trauma vivido, mas convergência do efeito traumático atual que faz com que ressurja no sujeito todas as suas relações com o seu próprio corpo. Isto quer dizer um certo tipo de demanda e determina um tipo de transferência particular entre médico e paciente.

Qual seria então este corpo da situação clínica?

$\mathrm{O}$ corpo da situação clínica não seria nem o puramente biológico, nem o puramente simbólico, mas uma forma de habitar o corpo biológico. Quer dizer, um corpo que é habitado e atravessado pela relação com o outro.

Neste sentido, tudo vai se prestar como cenário para reviver as cenas de dependência face ao outro, mas onde as trocas, as manipulações do corpo, passam pela reaparição de fantasmas de uma mãe ou de seus substitutos (a equipe médica em geral) vivida como uma mãe instável, que ataca, que abandona, que não pode assumir sua função de proteção.

A partir desta constatação, retrabalhamos os textos de Freud após os anos 20, onde as novas hipóteses sobre o trauma, o dualismo pulsional, a repetição, a angústia e o masoquismo foram pensadas. Além, é claro, da reflexão sobre os conceitos de trauma e clivagem que foram propostos nos últimos textos de Ferenczi.

Quando penso em meus pacientes, a situação da doença aparece fazendo efração no psiquismo do sujeito e mantendo-o prisioneiro desse efeito.

Como se opera esta "colagem" do real da doença e do corpo pulsional?

Quer dizer que a situação atual se apóia nas marcas reinvestidas do desenvolvimento pulsional, onde a relação com o outro operou, mas de um modo mórbido. O sujeito se encontra como em estado de guerra. Como em um estado onde ele é ejetado dele mesmo, mas ao mesmo tempo se identifica a um prejuízo, que é a reivindicação masoquista.

10. Isto nos coloca a interrogação necessária sobre onde se encontra o desejo da parte do analista. 


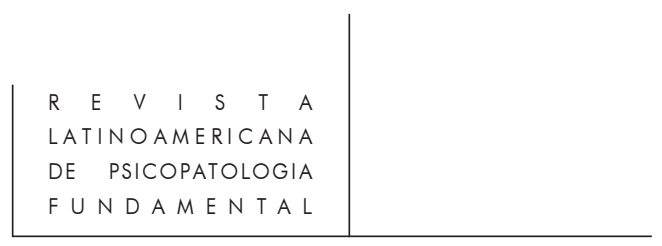

Apoiando-nos no que desenvolve Ferenczi, no seu jornal clínico ${ }^{11}$, esta parte ejetada, clivada, pode se manifestar por manifestações corporais, como se essa clivagem narcísica pudesse produzir um modo de "autocura" que permite ao sujeito narcisicamente ferido suportar o insuportável. O sujeito se cliva na tentativa de metabolizar a situação. A identificação ao agressor é a conseqüência deste movimento.

Somente quando as representações dadas pelo médico não são mais capazes de ajudar o sujeito a suportar seu estado de doença, o encaminhamento é efetuado. Muitas vezes esta derivação é recoberta por uma forma de reação terapêutica negativa através dos atos corporais: vômitos, febre, repetição da mesma situação etc. O corpo empresta o que não pode ser reconhecido como próprio. Por exemplo, na situação analítica o sujeito constrói todo seu discurso em torno do corpo doente. Essa reconstituição narcísica que, segundo o termo freudiano, chama-se contra-investimento, é necessária pois é o meio pelo qual a vida psíquica vai reagir face a efração sofrida. (segundo o modelo da vesícula viva) Desta forma, o empobrecimento da atividade psíquica, que poderia ser pensado como pensamento operatório, segundo a escola psicossomática francesa, não seria mais, a meu ver, um defeito elaborativo, mas uma forma de mobilização para contrainvestir o que foi rompido. Em termos pulsionais, como possibilidade de ligação.

O que o trabalho analítico vai poder introduzir é precisamente esta dimensão traumática e angustiante que se impõe no momento do diagnóstico.

A possibilidade de verbalizar e/ou reencenar na situação analítica esta situação de efração, de perda das figuras de proteção, pode permitir que o sujeito, na sua relação consigo mesmo, se distancie destas identificações com os fantasmas de destruição. Como um reinvestimento libidinal de sua representação de seu corpo. Num movimento de desligamento e ligação em termos pulsionais.

Gostaria de citar uma pequena passagem de uma situação vivida com uma paciente. Esta paciente, que se encontrava em psicoterapia já há algum tempo, na véspera de uma intervenção cirúrgica, e de acordo com uma fórmula que havíamos criado juntas ${ }^{12}$ me envia a seguinte mensagem:

Amanhã eu vou para o " $X$ " (hospital onde ocorreria a intervenção cirúrgica) para me operar na manhã do dia seguinte.

É mais ou menos a minha $25^{\underline{a}}$ operação, mas eu tenho sempre o mesmo sentimento em relação a anestesia, um medo que aumenta mais e mais até o momento fatal onde eu caio no grande vazio. Eu sei que no último momento não poderei me impedir de chorar porque o medo será forte e, bobamente, como

11. S. Ferenczi. Journal clinique, op. cit.

12. Escrever cartas, e, caso desejasse, enviá-las para mim. 
a cada vez, eu direi ao anestesista: "Senhor, tome conta de mim". É isto. É engraçado como lhe conto tudo, até as coisas de que tenho vergonha...

Espero que a Senhora receba esta mensagem a tempo. ${ }^{13}$

Nesse momento o trabalho do analista não é nada simples. Não somente ele pode ser colocado, através da situação transferencial, na posição de ator da violência que foi exercida, mas também desafiado nas suas capacidades de conter, de portar. Porque nesse contexto não somente a violência é a impossibilidade de subjetivação, mas uma sorte de ausência/presença necessária para fazer face ao insuportável.

Por exemplo, situações onde ocorre a sensação de aproximação o paciente pode viver como persecutório, ou, ocorrendo sensação de distanciamento, é vivido como abandono.

Então a perspectiva aberta por este trabalho é a de repensar o que constitui a idéia do quadro, do silêncio e do corpo, pois é de acordo com a nossa forma de conceber estes pontos que nossa escuta vai se estabelecer.

Quantas vezes eu me senti paralisada em minha capacidade de pensar, como se todo o meu corpo se achasse obrigado a não poder mais fazer um só movimento, numa mortificação que fazia despertar em mim, por exemplo, o desejo de terminar antes da hora a seção ou não mais entender o que era dito, ou, ainda, ficar numa vigilância obsessiva. Esta resposta contratransferencial corresponde a uma configuração transferencial que pretende uma série de situações para fazer sentir no outro o sofrimento que se encontra nele. Tudo se passa como se o sujeito desejasse que o analista sentisse essa situação de efração ao mesmo tempo que corresponde a uma demanda de uma ação específica para resolver sua própria situação, mas sem palavras, onde o corpo age.

O que posso dizer é que a confrontação com a minha impotência e o esfacelamento do corpo representavam uma confrontação radical com meus próprios componentes narcísicos e meus suportes teóricos. Como se o que se encontrava em jogo fosse a possibilidade de constituição mesmo do narcisismo.

Neste sentido, os trabalhos desenvolvidos por Winnicott, McDougall e Fédida são extremamente importantes, pois é na perspectiva da compreensão do que se passa no interior da situação clínica que se justifica toda a conceitualização em psicanálise. Quer dizer, a técnica não revela mais do saber do analista, mas de sua capacidade de experimentar uma série de afetos e distingui-los da compreensão dos afetos que formam sua personalidade. Desta forma poderia enfrentar a paralisação, resultado da ausência da palavra, e inaugurar um modo de transformar, resgatar a capacidade de operação da situação clínica.

13. A característica do correio na França é o recebimento das correspondências no dia seguinte ao do envio. 


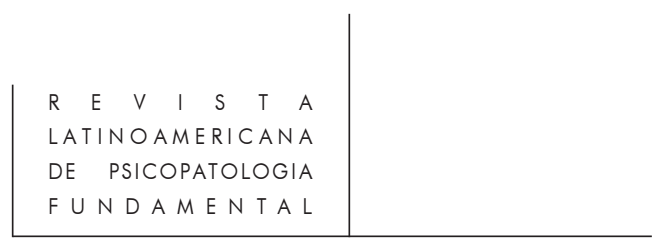

Assim, estes momentos de disfuncionamento, este conjunto de processos que se manifestam não somente em palavras, mas através do silêncio e do corpo obstinado, podem dar nascimento a instantes únicos onde a singularidade chega a se afirmar.

\section{Resumos}

Este artículo se dedica a trabajar la problemática y los efectos que se configuran en personas que se submeten al diagnóstico precoz del cancer. Se destaca una especificidad en el trabajo clínico psicoanalítico y se introduce una reflexión de la autora a partir del discurso de Freud después de los años 20. A través de algunas nociones, tales como traumatismo, masoquismo y repetición, así como también se coloca en el centro de la experiencia clínica los conceptos de trauma y clivage propuestos en los últimos textos de Ferenczi.

Estos conceptos apoyan la reflexión de la autora sobre la complejidad transferencial y contra-transferencial del trabajo psicoanalítico desarrollado con el paciente canceroso.

L'article présente l'intérêt de traiter de la problématique de effet du diagnostic du cancer, compte-tenu de la mise en place de techniques de detections precoces de cette maladie. Il en ressort une spécification de l'approche clinique psychanalytique, où l'auteur introduit une reflexion à partir du discours de Freud après les années 20. A travers certains notions telles que le traumatisme, le masochisme et la repetition, l'auteur met aussi au centre de son experience clinique les concepts de trauma et clivage proposés dans les derniers articles de Ferenczi.

Le cours à ces concepts soutiennent la reflexion de l'auteur sur la complexité transferentielle et contretransferentielles de la prise en charge psychanaslytique du patient cancereux.

This article looks upon the problems of the cancer diagnostic effects on people undergoing early detection techniques for this disease. A specificity of the psychoanalytic clinical work comes out, to which the author adds a reflection in accordance to Freud's discourse after the 1920s. Through some notions such as traumatism, masoquism and repetition, the concepts of trauma and cleavage, as proposed by Ferenczi in his late writings, are also brought into the heart of her clinical experience.

These concepts support the author's reflection upon the transferential and counter-transferential complexity of any psychoanalytic work on cancer patients. 